\title{
Falls in Older Adults: How to Asses and Prevent?
}

\author{
Natália Boneti Moreira* \\ Centro Universitário Dom Bosco (UniDBSCO), Universidade Federal do Paraná (UFPR), Brazil
}

Submission: March 29, 2018; Published: August 27, 2018

*Corresponding author: Natalia Boneti Moreira, Centro Universitário Dom Bosco (UniDBSCO), Universidade Federal do Paraná (UFPR), Brazil, Email: nataliaboneti@hotmail.com

\section{Opinion}

Falls and its related consequences are among the major elderly's public health worldwide problem [1-4]. Approximately $42 \%$ of elderly with 70 years or more have experienced at least one fall in the last twelve months [4]. A recent systematic review showed a higher risk-adjusted mortality in falls compared to motor vehicle collisions [3], increasing morbity and mortality in older adults $[3,5,6]$.

Several studies have demonstrated exponential growing risk of falls with increasing age $[3,7,8]$, not only by structural and physiological changes, but also by reduction of functionality and increasing of frailty $[4,5]$. Functionality is associated with elderly's function and physical capacities, as muscle potency, walking speed and functional mobility; and social and attitudinal environmental factors affecting them $[9,10]$, and the declines of these capacities have the potential to increase fall's risk and the severity of falling consequences in older adults [11].

Besides the physical consequences, falls lead to psychological and cognitive changes, as social isolation, depression, fear of falling [11-13] and reduction in quality of life [11,14]. It has been concluded that combination of these factors restrict their activities of daily living, social activities and health perception, making elderly's functionally dependent, and therefore, generating a negative social and economical impact on family, community and society $[4,11,13]$.

In this context, it's really important to assess the risk of falls and prevent these episodes. The multifactorial assessment identifies the risk factors for falling. The evaluation may include cognitive impairment, continence problems, falls history (involving causes and consequences, such as fear of falling and injuries), adequate use of footwear, home hazards (e.g. inadequate lightening, carpet or slippery floor, etc.), health problems that may increase their risk of falling (e.g., arterial hypertension, syncope syndrome, visual impairment, etc.), inadequate or excessive use of medication, postural instability, mobility problems and/or balance problems $[15,16]$.

All older adults with frequent falls or with increased risk of falling should be considered for an individualized multifactorial intervention composed by strength and balance training, home hazard assessment and intervention, vision assessment and referral, medication review with modification/withdrawal and psychological aspects including risk behavior and fear of falls. These aspects can avoid the reduction of physical activity level promoting independence and improving physical, psychological and social function, providing a better quality of life for older adults $[15,16]$.

\section{References}

1. Callis N (2016) Falls prevention: Identification of predictive fall risk factors. Applied Nursing Research 29: 53-58.

2. Howard BS, Beitman CL, Walker BA, Moore ES (2016) Cross-cultural Educational Intervention and Fall Risk Awareness. Physical \& Occupational Therapy In Geriatrics 34(1): 1-20.

3. Sammy I, Lecky F, Sutton A, Leaviss J, Cathain O (2016) Factors affecting mortality in older trauma patients-A systematic review and meta-analysis. Injury 47(6): 1170-1183.

4. WHO Global Report on Falls Prevention in Older Age (2007) World Health Organization, Geneva, Switzerland.

5. Ambrose AF, Cruz L, Paul G (2015) Falls and Fractures: A systematic approach to screening and prevention. Maturitas 82(1): 85-93.

6. Shier V, Trieu E, Ganz DA (2016) Implementing exercise programs to prevent falls: systematic descriptive review. Injury Epidemiology 3(1): 16.

7. Dinh MM, Roncal S, Byrne CM, Petchell J (2013) Growing trend in older patients with severe injuries: Mortality and mechanisms of injury between 1991 and 2010 at an inner-city major trauma centre. ANZ Journal of Surgery 83(1-2): 65-69.

8. Fatovich DM, Jacobs IG, Langford SA (2013) The effect of age, severity, and mechanism of injury on risk of death from major trauma in Western Australia. The journal of trauma and acute care surgery 74(2): 647-651.

9. Fox MH, Krahn GL, Sinclair LB, Cahill A (2015) Using the international classification of functioning, disability and health to expand understanding of paralysis in the United States through improved surveillance. Disability and Health Journal 8(3): 457-463.

10. World Health Organization (2016) The ICF: An Overview.

11. Smee DJ, Berry HL, Anson JM, Waddington GS (2015) The Relationship Between Subjective Falls-Risk Assessment Tools and Functional, Health-Related, and Body Composition Characteristics. Journal of Applied Gerontology 36(2): 156-172. 
12. Chang VC, Do MT (2015) Risk Factors for Falls Among Seniors: Implications of Gender. American Journal of Epidemiology 181 (7): 521-531.

13. Pohl P, Sandlund M, Ahlgren C, Bergvall-Kareborn B, Lundin-Olsson L, et al. (2015) Fall risk awareness and safety precautions taken by older community-dwelling women and men-a qualitative study using focus group discussions. PLoS ONE 10(3): 1-15.

14. Wiens CA, Koleba T, Jones CA, Feeny DF (2006) The Falls Risk Awareness Questionnaire: development and validation for use with older adults. Journal of gerontological nursing 32(8): 43-51.
15. AGS, BGS, AAOSPFP (2001) Guideline for the Prevention of Falls in Older Persons. Journal of the American Geriatrics Society 49: 664-672.

16. National Institute for Health and Care Excellence (2018) Falls in older people: assessing risk and prevention. Clinical Guideline. National Institute for Health and Care Excellence. 